\title{
An Empirical Analysis on the Nonlinear Relationship Between Economic Growth and Carbon Dioxide Emissions in China
}

\author{
Yiqiong $\mathrm{Lu}^{1,2}$ \\ ${ }^{1}$ School of Environment \& Natural Resources, Renmin University of China, Beijing 100086, China \\ ${ }^{2}$ Safety and Environmental Supervision Department, China Energy Investment Corporation, Beijing 100011, China
}

Corresponding Author Email: yiqiong.lu@chnenergy.com.cn

https://doi.org/10.18280/ijsdp.150210

Received: 20 May 2019

Accepted: 8 January 2020

\section{Keywords:}

economic growth, carbon dioxide $\left(\mathrm{CO}_{2}\right)$ emissions, environmental Kuznets curve $(E K C)$ theory, spatial panel data model

\begin{abstract}
Based on the traditional theory of environmental Kuznets curve (EKC), this paper selects the panel data in 2000-2017 of 30 provincial administrative regions (provinces) in China as objects, and estimates the per capita carbon dioxide $\left(\mathrm{CO}_{2}\right)$ emissions of each province. On this basis, an EKC econometric model with spatial effect was established, and used to empirically analyze the nonlinear relationship between economic growth and $\mathrm{CO}_{2}$ emissions. The main results are as follows: (1) The provinces differed greatly in per capita $\mathrm{CO}_{2}$ emissions; the per capita $\mathrm{CO}_{2}$ emissions of Inner Mongolia, Ningxia, Shanxi, Tianjin, and Liaoning were relatively high, while those of Hunan, Jiangxi, Guangxi, Sichuan and Hainan were relatively low. (2) In addition to obvious spatial correlation, the per capita $\mathrm{CO}_{2}$ emissions of the provinces have spatial heterogeneity: most provinces belong to cluster areas, but only a few fall in the areas of spatial outliers. (3) The EKC spatial econometric model shows that the economic growth has a significant inverted $\mathrm{U}$ relationship with $\mathrm{CO}_{2}$ emissions. In other words, with the growth in economy, the $\mathrm{CO}_{2}$ emissions firstly increase and then decrease. (4) $\mathrm{CO}_{2}$ emissions are clearly promoted by industrial structure, energy consumption structure and environmental regulation, but suppressed by the level of opening.
\end{abstract}

\section{INTRODUCTION}

Over the past four decades, the rapid economic growth is a mixed blessing to China. On the upside, a huge amount of economic wealth is accumulated; on the downside, lots of energy is consumed, emitting a massive amount of carbon dioxide $\left(\mathrm{CO}_{2}\right)$. According to statistics from Carbon Brief, China released a staggering amount of 9.8 billion tons of $\mathrm{CO}_{2}$ in 2017 , up by $1.7 \%$ from the amount of the previous year. In 2010, China surpassed the US for the first time as the largest carbon emitter in the world. Currently, the $\mathrm{CO}_{2}$ emissions of China accounts for $28 \%$ of the global total, more than those of the US (14\%) and the EU (12\%) combined. The heavy $\mathrm{CO}_{2}$ emissions intensify the greenhouse effect and seriously affect our daily lives. On the UN Climate Change Conference 2009 in Copenhagen, China promised to reduce the $\mathrm{CO}_{2}$ emission per unit of gross domestic product (GDP) by $40-45 \%$ before 2020. To honor the promise, China must withstand a huge pressure on carbon reduction.

Meanwhile, China's economic growth is still featured by high investment, pollution and emissions, under the driving forces of investment and industrialization. These features are expected to remain for quite a long time. Therefore, it is a key issue for governments at all levels in China to strike a balance between economic growth and $\mathrm{CO}_{2}$ emissions. In other words, the governments and the academia must work together to ensure the healthy development of national economy, while slashing $\mathrm{CO}_{2}$ emissions. To formulate reasonable carbon reduction policies, the governments at all levels in China must explore deep into the following questions: What is the relationship between economic growth and $\mathrm{CO}_{2}$ emissions in China? Is it linear or nonlinear? What are the factors that affect $\mathrm{CO}_{2}$ emissions, other than economic growth?

The relationship between economic growth and $\mathrm{CO}_{2}$ emissions has long been a research hotspot. According to the relevant literature, there are four different conclusions about the relationship. Some scholars found that economic growth has a purely linear relationship with $\mathrm{CO}_{2}$ emissions, i.e. $\mathrm{CO}_{2}$ emissions continue to increase with the growth of economy [1, 2].

Some scholars held that economic growth has a typical nonlinear relationship with $\mathrm{CO}_{2}$ emissions. The most popular theory is the environmental Kuznets curve (EKC). Proposed by Grossma and Krueger [3], the EKC theory describes the relationship between economic growth and $\mathrm{CO}_{2}$ emissions as an inverted $U$ curve. This description is widely received among scholars. For example, Lindmark [4], Nasir and Rehaman [5] established time series models for EKC-based empirical research, and validated the inverted $U$ relationship between economic growth and $\mathrm{CO}_{2}$ emissions in countries like Sweden, Pakistan and Spain. Through empirical analyses on China, Jalil and Mahmud [6], Du and Wei [7], Wang et al. [8], and $\mathrm{Hu}$ et al. [9] confirmed that the relationship between economic growth and $\mathrm{CO}_{2}$ emissions in China also exhibits as an inverted $U$ curve.

Some scholars illustrated the relationship between economic growth and $\mathrm{CO}_{2}$ emissions as other types of curves. Dinda [10], McConnell [11], Stem [12], and Task and Zaim [13] suggested that the relationship between long-term economic growth and $\mathrm{CO}_{2}$ emissions takes the form of an 
inverted $\mathrm{N}$ curve, a positive $\mathrm{N}$ curve or an $\mathrm{M}$ curve, rather than the inverted $\mathrm{U}$ curve.

Some scholars argued that economic growth has nothing to do with $\mathrm{CO}_{2}$ emissions. For instance, Wang [14] carried out an EKC-based analysis on the panel data in 1971-2007 of 98 countries, revealing that economic growth is not correlated with $\mathrm{CO}_{2}$ emissions.

To sum up, Chinese and foreign scholars have explored deep into the relationship between economic growth and $\mathrm{CO}_{2}$ emissions, especially from the angle of the EKC. However, there is a major defect with the EKC-based research: the traditional EKC theory assumes that regional $\mathrm{CO}_{2}$ emissions are spatially independent of each other. In simple terms, the $\mathrm{CO}_{2}$ emissions of a region have a significant impact on that region, but a negligible impact on the surrounding regions.

Anselin and Rey [15] clearly pointed out that all data are correlated in space, especially $\mathrm{CO}_{2}$ emissions. As an important greenhouse gas (GHG), $\mathrm{CO}_{2}$ naturally has a certain degree of spatial spillover. The spatial correlation of $\mathrm{CO}_{2}$ emissions is enhanced by the pollution transfer policies between regions. Moreover, China is undergoing the rapid integration of regional economies. The spatial dependence between regions grows continuously, due to the environmental cooperation and technology diffusion across regions.

Therefore, the spatial correlation between regions must be considered before examining the relationship between economic growth and $\mathrm{CO}_{2}$ emissions. Otherwise, there might be large errors in the research results. On this basis, this paper introduces the spatial correlation between regions to the empirical verification of the EKC assumption on the relationship between economic growth and $\mathrm{CO}_{2}$ emissions.

\section{METHODOLOGY}

\subsection{Estimation method for $\mathrm{CO}_{2}$ emissions}

The annual report from the World Bank shows that, in most countries, $70 \%$ of $\mathrm{CO}_{2}$ emissions come from the consumption of fossil energy. The proportion is as high as $90 \%$ in China, for the energy structure is dominated by fossil energy like coal and petroleum. Since China's National Bureau of Statistics has not released the data on $\mathrm{CO}_{2}$ emissions in each provincial administrative regions (hereinafter referred to as provinces), most Chinese scholars estimated $\mathrm{CO}_{2}$ emissions based on the consumption of fossil energy [16]. Following this best practice, this paper estimates $\mathrm{CO}_{2}$ emissions according to Section 6, Vol. 2 of the IPCC 2006 Guidelines for National Greenhouse Gas Inventories:

$$
\mathrm{CO}_{2}=\sum_{i=1}^{14} E_{i} \times N C V_{i} \times C E F_{i} \times C O F_{i} \times(44 / 12)
$$

where, $\mathrm{CO}_{2}$ is the $\mathrm{CO}_{2}$ emissions to be estimated; $i$ is the type of energy; $E$ is the total consumption of all types of energies; $N C V$ is the net calorific value of each type of energy; $C E F$ is carbon emissions coefficient; $C O F$ is carbon oxidation factor of each type of energy; 44 and 12 are the molecular weights of $\mathrm{CO}_{2}$ and carbon, respectively.

According to the consumption data released by China's National Bureau of Statistics, $i=1,2, \ldots, 14$. Where, 1-14 represent coal, coke, coke oven gas, blast furnace gas, converter gas, other gases, crude oil, gasoline, kerosene, diesel, fuel oil, liquefied petroleum gas, natural gas and liquefied natural gas, respectively. For simplicity, the consumptions of different types of energies, which are measured in different units, were converted by the standard coal coefficients (unit: $10,000 \mathrm{TCE}$ ) and added up to obtain the $E$ value. The $N C V$ was obtained by converting the consumption of each type of energy to the unit TJ.

\subsection{Spatial autocorrelation coefficient and local indicators of spatial association (LISA)}

This paper mainly examines the relationship between economic growth and $\mathrm{CO}_{2}$ emissions. Here, $\mathrm{CO}_{2}$ emissions specifically refer to the per capita $\mathrm{CO}_{2}$ emissions in each province. To construct a robust EKC model, it is necessary to confirm whether the per capita $\mathrm{CO}_{2}$ emissions of different provinces have significant spatial correlation (spatial dependence). The spatial correlation is a spatial attribute of per capita $\mathrm{CO}_{2}$ emissions, that is, the clustering of provincial per capita $\mathrm{CO}_{2}$ emissions in space. In other words, the per capita $\mathrm{CO}_{2}$ emissions of neighboring provinces are highly similar, due to the spatial spillover effect.

Generally, spatial correlation is measured by the spatial autocorrelation coefficient: Global Moran's I [17]:

$$
\text { Moran's } I=\frac{n}{\sum_{i=1}^{n}\left(x_{i}-\bar{x}\right)^{2}} \frac{\sum_{i=1}^{n} \sum_{j=1}^{n} W_{i j}\left(x_{i}-\bar{x}\right)\left(x_{j}-\bar{x}\right)}{\sum_{i=1}^{n} \sum_{j=1}^{n} W_{i j}}
$$

where, $W_{i j}$ is the spatial weight matrix consisting of zeros and ones; $x_{i}$ and $x_{j}$ are the observations of provinces $i$ and $j$, respectively; $\bar{x}=\left(\Sigma_{i} x_{i}\right) / n$ is the mean observation of all provinces.

Global Moran's I generally falls within $[-1,1]$. If the index is -1 , the observations are completely negatively correlated in space; if the index is 1 , the observations are completely positively correlated in space; if the index is 0 , the observations are completely uncorrelated in space.

Once its value is determined, Global Moran's I must subject to authenticity test, using the Z-score normal distribution. The index will pass the authenticity test, if its value is significant on three levels: $10 \%, 5 \%$ and $1 \%$. The Z-score can be expressed as:

$$
Z(d)=\frac{[\text { Global Moran's I }-E(\text { Global Moran's I })]}{\sqrt{\text { VAR(Global Moran's I })}}
$$

Global Moran's I demonstrates whether the provinces have spatial correlation in $\mathrm{CO}_{2}$ emissions on the global scale, failing to reflect the spatial distribution of each province in local areas. To solve the problem, Local Moran's I, a.k.a. local indicators of spatial association (LISA), was introduced to disclose the distribution of each province in the four quadrants $(\mathrm{H}-\mathrm{H}, \mathrm{L}-\mathrm{H}$, L-L, H-L) of the spatial coordinate system [18]:

$$
\text { Local Moran's } I=\frac{n^{2}}{\sum_{i=1}^{n}\left(x_{i}-\bar{x}\right)^{2}} \frac{\left(x_{i}-\bar{x}\right) \sum_{i=1}^{n} \sum_{j=1}^{n} W_{i j}\left(x_{j}-\bar{x}\right)}{\sum_{i=1}^{n} \sum_{j=1}^{n} W_{i j}}
$$

\subsection{EKC Theory}

The relationship between economic growth and environmental pollution has always been in the limelight. In 
1993, Grossman and Krueger proposed the EKC, attracting much attention from the academia. According to the EKC theory, a country or region has relatively light environmental pollution, when the economy just starts to develop. But as the economy takes off, both income and resource consumption will increase gradually, causing greater pollution to the environment. In this stage, economic growth is positively correlated with environmental pollution. With further growth in economy, the income will reach an inflection point or critical value. Then, people will realize the importance of environmental protection, and take multiple measures to curb the emissions of pollutants to the environment. In this stage, economic growth is negatively correlated with environmental pollution. Overall, the relationship between economic development and environmental pollution is not purely linear, but an inverted $U$ curve.

The EKC theory confirms the existence of a long-term internal relationship between economic growth and environmental protection. But this does not necessarily mean that environmental quality will improve with the rising income. The government's economic measures or environmental policies also directly bear on the environment.

In the light of Grossman and Krueger [3] and Coal [19], the traditional EKC model between economic growth and environmental pollution can be expressed as:

$$
Y=\beta_{0}+\beta_{1} x+\beta_{2} x^{2}+\mu
$$

where, $Y$ is the index of environmental pollution (e.g. per capita $\mathrm{CO}_{2}$ emissions); $x$ is the index of economic growth (e.g. per capita GDP; $\mu$ is a random perturbation; $\beta_{0}$ is a constant; $\beta_{1}$ and $\beta_{2}$ are the parameters of the first- and second-order terms of economic growth, respectively.

The relationship between environmental pollution and economic growth depends on the values of $\beta_{0}, \beta_{1}$ and $\beta_{2}$ :

(1) If $\beta_{0} \neq 0$ and $\beta_{2} \neq 0$, there is a purely linear relationship between $Y$ and $x$ : with the growth in economy, environmental pollution either improves or worsens.

(2) If $\beta_{l}>0$ and $\beta_{2}<0$, there is an inverted $U$ relationship between $Y$ and $x$ : as the economy starts to develop, environmental pollutants increase with the rapid economic growth; once the economy reaches an advanced level, pollutant emissions will drop with further economic growth. This relationship is the basic form of the EKC model.

(3) If $\beta_{1}<0$ and $\beta_{2}>0$, there is a $U$ relationship between $Y$ and $x$ : as the economy starts to develop, economic growth alleviates environmental pollution; once the economy reaches an advanced level, economic growth causes environmental deterioration.

(4) If $\beta_{0} \neq 0$ and $\beta_{l} \neq 0$, there is no correlation between $Y$ and $x$ : economic growth has no impact on environmental pollution.

\subsection{EKC spatial econometric model}

In the traditional EKC model, the relationship between economic growth and environmental pollution is discussed under the assumption that the objects are independent of each other, with no heterogeneity in spatial distribution. That is to say, the spatial correlation has no effect. The assumption obviously goes against the reality. What is worse, the traditional EKC model uses the ordinary least squares (OLS) method in regression estimation. Thus, the spatial autocorrelation test on model residuals is often ignored, leading to large deviations in the estimation results of the model. To overcome the above defects, the spatial effect should be included in the traditional EKC model, creating an EKC spatial econometric model.

Currently, there are two main types of spatial econometric models: spatial autoregressive (SAR) model and spatial error model (SEM). The SAR model can be expressed as [20]:

$$
\left\{\begin{array}{l}
y=\rho W_{1} y+X \beta+u \\
u=\lambda W_{2}+\varepsilon \\
\varepsilon \sim N\left(0, \sigma_{\varepsilon}^{2} I_{n}\right)
\end{array}\right.
$$

where, $y$ is the explained variable; $X$ is the set of explanatory variables; $\rho$ and $\lambda$ are parameters of spatial weight matrix, reflecting the spatial autoregressive property of the model space; $\mathrm{W}$ is an $n \times n$ spatial weight matrix of zeros and ones; $W$ $y$ is the product of spatial weight matrix and explained variable, i.e. the degree of influence of spatial correlation on model; $\varepsilon$ is a random error.

The SEM can be expressed as [21]:

$$
\left\{\begin{array}{l}
y=X \beta+\varepsilon \\
u=\lambda W_{1} \varepsilon+\mu \\
\varepsilon \sim N\left(0, \sigma_{\varepsilon}^{2} I_{n}\right)
\end{array}\right.
$$

where, $\lambda$ is the spatial error coefficient of an $n \times 1$-order space, reflecting the degree of spatial autocorrelation for the residual terms of the model; $\mu$ is a normally distributed random error; $\beta$ is the estimation parameter of each explanatory variable, reflecting the degree of influence of each explanatory variable over the explained variable.

Besides economic growth, $\mathrm{CO}_{2}$ emissions are also influenced by such factors as industry, energy and policy. Hence, four influencing factors were included in the EKC model as control variables:

(1) Industrial structure (IND)

The proportion of different industries in the national economy is closely related to $\mathrm{CO}_{2}$ emissions. The secondary industry consumes much more energy than primary and tertiary industries. Therefore, the proportion of secondary industry in the national economy is positively correlated with $\mathrm{CO}_{2}$ emissions.

(2) Energy consumption structure (ECS)

China is a large consumer of coal, a high-carbon energy source. The energy consumption structure can be measured by the proportion of coal in the total amount of energies being consumed. The greater the proportion is, the higher the $\mathrm{CO}_{2}$ emissions.

(3) Level of opening (OPL)

The growing level of opening, especially the rise of import/export trade, helps the host country to introduce and absorb advanced low-carbon technologies and management skills. In this way, the regional energy consumption will become less intense, which promotes energy-saving and emissions reduction.

(4) Environmental regulation (ERS)

The Chinese government uses environmental regulation as a macro-control tool to protect the environment. In general, the $\mathrm{CO}_{2}$ emissions of enterprises are controlled by pollution charging system and emissions trading system. 
Based on the above control variables and formulas (5)-(7), an EKC spatial econometric model (a general fixed spatial effect model) was established for the relationship between economic growth (per capita GDP) and environmental pollution (per capita $\mathrm{CO}_{2}$ emissions):

$$
\begin{aligned}
& \operatorname{LnPCO}_{2 i, t}=\alpha_{i}+\phi_{t}+\beta_{1} \operatorname{LnPGDP}_{i, t}+ \\
& \beta_{2} \operatorname{Ln}\left(\mathrm{PGDP}_{i, t}\right)^{2}+\beta_{3} \operatorname{LnIND}_{i, t}+\beta_{4} \operatorname{LnECS}_{i, t}+ \\
& \quad \beta_{5} \operatorname{LnOPL}_{i, t}+\beta_{6} \operatorname{LnERS}_{i, t} \\
& +\delta \sum_{j} W_{i j}\left(P C O_{2 i, t}\right)+\mu_{i, t} \\
& \mu_{i, t}=\lambda \sum_{j} W_{i j} * u_{i, t}+\varepsilon_{i, t}
\end{aligned}
$$

where, $\alpha_{i}$ and $\phi_{t}$ are fixed spatial effect and fixed time effect, respectively; $\delta$ and $\lambda$ are spatial autoregressive coefficient and spatial error coefficient, respectively. Both $\delta$ and $\lambda$ are related to spatial correlation in the model. If $\delta$ is zero and significant, then the model is an SEM; if $\lambda$ is zero and significant, then the model is an SAR model.

The explained variable of the model is $\mathrm{PCO}_{2}$ : the ratio of the estimated $\mathrm{CO}_{2}$ emissions of a province to the year-end resident population of that province.

The main explanatory variables of the model are the firstand second-order terms of per-capita GDP (PGDP). The estimation coefficients of the two terms reflect the form of the EKC.

The control variables of the model include industrial structure (IND) (the proportion of the total output of secondary industry in a province to the GDP of that province), energy consumption structure (ECS) (the proportion of coal consumption to the total energy consumption in each province), level of opening (OPL) (the ratio of the total import/output value, which is converted from USD into RMB at the mean exchange rate, to the GDP in each province), and environmental regulation (ERS) (the ratio of the investment on industrial pollution control to the total industrial output, measured in the unit of $10^{4}$ yuan, in each province).

\subsection{Data sources}

Considering data availability and completeness, the panel data in 2000-2017 of 30 Chinese provinces were selected for our research. Tibet, Hong Kong, Macao and Taiwan were excluded, because the data on these provinces are incomplete. The research data were collected from the China Statistical Yearbook, China Statistical Yearbook on Environment, China Energy Statistical Yearbook, and local statistical yearbooks. The collected data mainly cover the following variables: different types of energies, GDP, per capita GDP, year-end resident population, total output of secondary industry, total import/export value, investment on industrial pollution control, and total industrial output.

\section{RESULTS}

\subsection{Province difference in per capita $\mathrm{CO}_{2}$ emissions}

Based on the data of various energies, the $\mathrm{CO}_{2}$ emissions of the 30 provinces were estimated by formula (1). Then, the $\mathrm{CO}_{2}$ emissions of each province were divided by the year-end resident population, yielding the per capita $\mathrm{CO}_{2}$ emissions of each province. The mean per capita $\mathrm{CO}_{2}$ emissions of each province in 2000-2017 is displayed in Figure 1.

It can be seen that the provinces differed greatly in per capita $\mathrm{CO}_{2}$ emissions. The top 5 provinces in per capita $\mathrm{CO}_{2}$ emissions are Inner Mongolia, Ningxia, Shanxi, Tianjin, and Liaoning. The per capita $\mathrm{CO}_{2}$ emissions of these provinces were all above 9.5 tons. The high per capita $\mathrm{CO}_{2}$ emissions can be explained as follows: Located in central and western regions, Inner Mongolia, Ningxia, and Shanxi are major coal producers in China. In recent years, a huge amount of coal has been consumed by the booming industry, emitting a lot of $\mathrm{CO}_{2}$. Tianjin and Liaoning are coastal provinces in the eastern region. The two provinces have a large demand for fossil energy, because their industrial systems are complete and dominated by heavy industry.

Hunan, Jiangxi, Guangxi, Sichuan, and Hainan were the bottom five provinces in the ranking of per capita $\mathrm{CO}_{2}$ emissions. The per capita $\mathrm{CO}_{2}$ emissions of these provinces were below 3.5 tons. The low per capita $\mathrm{CO}_{2}$ emissions are attributable to the following factors: The five provinces consume relatively little fossil energy, because of their relatively backward economy, late start of industrial system, and low proportion of heavy industry. Located in the southern region, these provinces boast abundant hydropower resources, and their energy structure is mainly supported by hydropower.

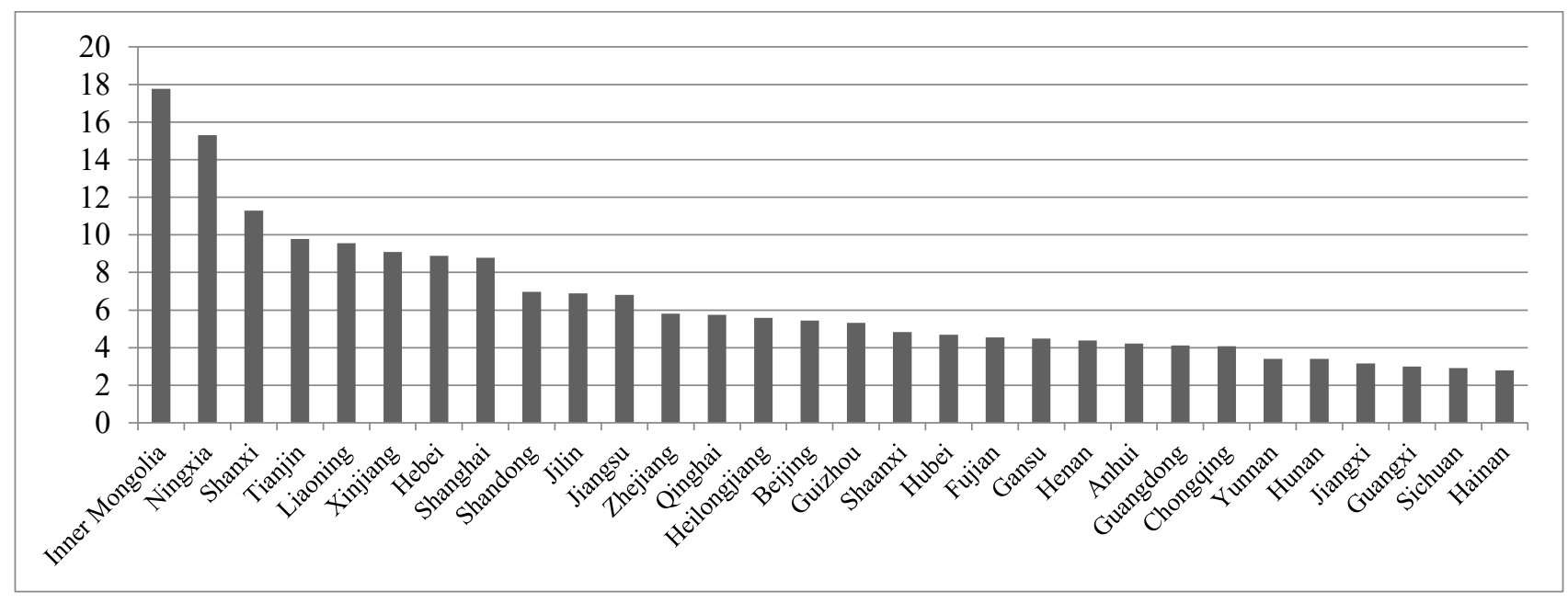

Figure 1. The mean per capita $\mathrm{CO}_{2}$ emissions of each province in 2000-2017 (unit: ton) 


\subsection{Spatial effect of per capita $\mathrm{CO}_{2}$}

Based on the spatial weight matrix of zeros and ones, GeoDa software was adopted to compute the Global Moran's I values of the per capita $\mathrm{CO}_{2}$ emissions of 30 provinces in 2000-2017. The results in Table 1 show that the Global Moran's I values of provincial per capita $\mathrm{CO}_{2}$ emissions were always positive, passing the significance test on the $5 \%$ or $1 \%$ level. This means the per capita $\mathrm{CO}_{2}$ emissions of different provinces have obvious spatial correlation, which greatly affect the changes in provincial per capita $\mathrm{CO}_{2}$ emissions. Further, it can be concluded that the provincial per capita $\mathrm{CO}_{2}$ emissions are distributed as clusters, instead of a random and free form; the per capita $\mathrm{CO}_{2}$ emissions of neighboring provinces are similar to each other. Therefore, the spatial effect must be included in the traditional EKC model, before probing into the relationship between economic growth and $\mathrm{CO}_{2}$ emissions. Otherwise, the model estimation will have significant deviations.

Table 1. Global Moran's I values of provincial per capita $\mathrm{CO}_{2}$ emissions in 2000-2017

\begin{tabular}{cccccc}
\hline Year & Global Moran's I & Error $(I)$ & Standard deviation (I) & Mean & P-value \\
\hline 2000 & 0.3841 & -0.0345 & 0.1203 & -0.0370 & 3.5004 \\
2001 & 0.3559 & -0.0345 & 0.1233 & -0.0329 & 3.1533 \\
2002 & 0.3298 & -0.0345 & 0.1202 & -0.0395 & 3.0724 \\
2003 & 0.2861 & -0.0345 & 0.1179 & -0.0356 & 2.7286 \\
2004 & 0.4201 & -0.0345 & 0.1202 & -0.0450 & 3.8694 \\
2005 & 0.4103 & -0.0345 & 0.1249 & -0.0280 & 3.5092 \\
2006 & 0.3293 & -0.0345 & 0.1211 & -0.0342 & 3.0017 \\
2007 & 0.3833 & -0.0345 & 0.1159 & -0.0394 & 3.6471 \\
2008 & 0.3586 & -0.0345 & 0.1096 & -0.0377 & 3.6159 \\
2009 & 0.3323 & -0.0345 & 0.1093 & -0.0321 & 3.3339 \\
2010 & 0.3814 & -0.0345 & 0.1107 & -0.0351 & 3.7624 \\
2011 & 0.3146 & -0.0345 & 0.1065 & -0.0375 & 3.3061 \\
2012 & 0.3197 & -0.0345 & 0.1072 & -0.0364 & 3.3218 \\
2013 & 0.3440 & -0.0345 & 0.1093 & -0.0330 & 3.4492 \\
2014 & 0.3412 & -0.0345 & 0.1159 & -0.0359 & 3.2537 \\
2015 & 0.3214 & -0.0345 & 0.1105 & -0.0344 & 3.2199 \\
2016 & 0.307 & -0.0345 & 0.1137 & -0.0316 & 2.9780 \\
2017 & 0.2621 & -0.0345 & 0.1072 & -0.0427 & 2.8433 \\
\hline
\end{tabular}

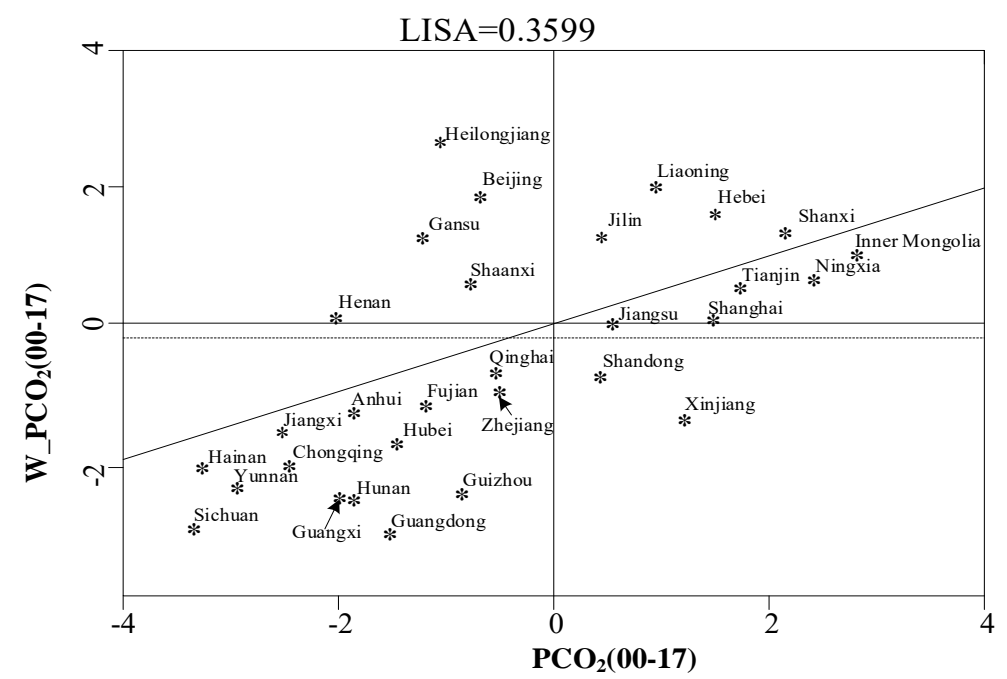

Figure 2. The LISA scatter plot for the mean per capita $\mathrm{CO}_{2}$ emissions of each province in 2000-2017

The next step is to observe the local distribution of provincial per capita $\mathrm{CO}_{2}$ emissions in space. The LISA scatter plot (Figure 2) was prepared for the mean per capita $\mathrm{CO}_{2}$ emissions of each province. There are four quadrants in the scatter plot: the first quadrant is the cluster area of high values $(\mathrm{HH})$; the second quadrant is an area of spatial outliers; the third quadrant is the cluster area of low values (LL); the fourth quadrant is another area of spatial outliers.

In the first quadrant, the per capita $\mathrm{CO}_{2}$ emissions of a province and its neighbors are both high; in the second quadrant, the per capita $\mathrm{CO}_{2}$ emissions of a province are high, while those of its neighbors are low; in the third quadrant, the per capita $\mathrm{CO}_{2}$ emissions of a province and its neighbors are both low; in the fourth quadrant, the per capita $\mathrm{CO}_{2}$ emissions of a province are low, while those of its neighbors are high. The provinces falling in the first and third quadrants belong to typical cluster areas, while those falling in the second and fourth quadrants belong to atypical areas of spatial outliers.

As shown in Figure 2, 30\% of all provinces fell in the first quadrant, including Inner Mongolia, Ningxia, Tianjin, Shanghai, Jiangsu, Shanxi, Hebei, Liaoning and Jilin; these provinces belong to the typical cluster area of high values. $16.67 \%$ of all provinces fell in the second quadrant, including Heilongjiang, Gansu, Beijing, Shaanxi and Henan; these 
provinces belong to an atypical area of spatial outliers. $46.66 \%$ of all provinces fell in the third quadrant, including Qinghai, Zhejiang, Anhui, Chongqing, Fujian, Hubei, Guizhou, Jiangxi, Yunnan, Hunan, Guangdong, Hainan, Sichuan, and Guangxi; these provinces belong to the typical cluster area of low values. $6.67 \%$ of all provinces fell in the fourth quadrant, including Shandong and Xinjiang; the two provinces belong to another atypical area of spatial outliers.

To sum up, the per capita $\mathrm{CO}_{2}$ emissions of most (76.66\%) provinces fell in the first and third quadrants, i.e. typical cluster areas, while only $23.34 \%$ provinces fell in the second and fourth quadrants. The results afford evidence as to the local spatial heterogeneity of provincial per capita $\mathrm{CO}_{2}$ emissions in China.

\subsection{Empirical results of EKC spatial econometric model}

This paper first performs regression analysis on model (8) by the OLS, and then uses Matlab 7.12 to test the significance of the spatial autocorrelation of the residual terms of the model. The estimated results are listed in Table 2.

To prove the necessity of controlling the fixed effects, Table 2 also provides the estimated results of the non-fixed effect models, the spatial fixed effects model, the time fixed effects model and the two-way fixed effects model. The results of the four models were compared to reveal the importance of controlling the fixed effects to model accuracy.

Table 2. Estimated and test results of general panel data models

\begin{tabular}{|c|c|c|c|c|}
\hline Variables & Non-fixed effects model & Spatial fixed effects model & Time fixed effects model & Two-way fixed effects model \\
\hline \multirow{2}{*}{$L n P G D P$} & -0.1803 & $1.2823^{* * *}$ & 0.2101 & $0.8187^{* * *}$ \\
\hline & $(-0.4695)$ & $(6.8059)$ & $(0.5328)$ & $(4.3577)$ \\
\hline \multirow{2}{*}{$\operatorname{Ln}\left(P G D P^{2}\right)$} & $0.0420^{* *}$ & $-0.0365^{* * *}$ & $0.0371^{* *}$ & $-0.0196^{* *}$ \\
\hline & $(2.1721)$ & $(-3.8182)$ & $(1.9031)$ & $(-1.9543)$ \\
\hline \multirow{2}{*}{$\operatorname{LnIND}$} & $0.2155^{* * *}$ & $0.3726^{* * *}$ & $0.1314^{*}$ & $0.4572^{* * *}$ \\
\hline & $(2.7100)$ & $(6.7890)$ & $(1.7217)$ & $(6.5452)$ \\
\hline \multirow{2}{*}{ LnECS } & $0.6623^{* * *}$ & $0.3781^{* * *}$ & $0.6172^{* * *}$ & $0.4001^{* * *}$ \\
\hline & $(14.5124)$ & $(13.02886)$ & $(14.6187)$ & $(14.5715)$ \\
\hline \multirow{2}{*}{ LnOPL } & -0.0165 & -0.0102 & $-0.1271^{* * *}$ & -0.0147 \\
\hline & $(-1.0036)$ & $(-0.5242)$ & $(-5.3647)$ & $(-0.7358)$ \\
\hline \multirow{2}{*}{ LnERS } & $0.2008^{* * *}$ & $0.0518^{* * *}$ & $0.2728^{* * *}$ & $0.0696^{* * *}$ \\
\hline & $(11.5285)$ & $(6.4450)$ & $(14.0328)$ & $(6.7079)$ \\
\hline$R$-squared & 0.7642 & 0.9181 & 0.6985 & 0.9614 \\
\hline $\log -L$ & 121.8205 & 398.1032 & 73.1410 & 437.2438 \\
\hline$D W$ & 1.0181 & 2.0464 & 1.4857 & 2.3901 \\
\hline LM-lag & $74.1350^{* * *}$ & $14.1730^{* * *}$ & $62.7034^{* * *}$ & 0.2481 \\
\hline Robust LM-lag & 1.7872 & $11.2657^{* * *}$ & $25.9982^{* * *}$ & $5.5222^{* *}$ \\
\hline LM-err & $158.2981^{* * *}$ & $4.7148^{* *}$ & $38.2598^{* * *}$ & $5.4157^{* *}$ \\
\hline Robust LM-err & $85.9503^{* * *}$ & 1.8075 & 1.5545 & $10.6898^{* * *}$ \\
\hline
\end{tabular}

Note: The bracketed data are t-test results; ${ }^{*}, *$, and $* * *$ are significance levels of $10 \%, 5 \%$ and $1 \%$; model estimation and spatial autocorrelation test were conducted on Matlab 7.12.

Table 3. Estimated and test results of spatial econometric models with two-way fixed effects

\begin{tabular}{ccc}
\hline Variables & SAR & SEM \\
\hline LnPGDP & $0.8621^{* * *}$ & $0.9528^{* * *}$ \\
& $(4.4232)$ & $(5.5463)$ \\
Ln $\left(P G D P^{2}\right)$ & $-0.0217^{* *}$ & $-0.0282^{* * *}$ \\
& $(-2.1132)$ & $(-3.0526)$ \\
LnIND & $0.4513^{* * *}$ & $0.4721^{* * *}$ \\
& $(6.4189)$ & $(6.7460)$ \\
LnECS & $0.4020^{* * *}$ & $0.4032^{* * *}$ \\
& $(14.6359)$ & $(15.2782)$ \\
LnOPL & -0.0155 & $-0.0384^{* *}$ \\
& $(-0.7773)$ & $(-1.9955)$ \\
LnERS & $0.0694 * * *$ & $0.0667^{* * *}$ \\
& $(6.7283)$ & $(6.5721)$ \\
$W^{*}$ dep.var. & -0.0299 & \\
spat.aut. & $(-0.6442)$ & $-0.2100^{* * *}$ \\
$R$-squared & & $(-3.4133)$ \\
Log-L & 0.9703 & 0.9702 \\
\end{tabular}

Note: The bracketed data are t-test results; *, **, and *** are significance levels of $10 \%, 5 \%$ and $1 \%$.

As shown in Table 2, the coefficients of determination, i.e. R-squared, of the non-fixed effect models, the spatial fixed effects model, the time fixed effects model and the two-way fixed effects model were $0.7642,0.9181,0.6985$ and 0.9614 , respectively. The two-way fixed effects model had the largest coefficient of determination, and thus the best goodness of fit. The two-way fixed effects model also achieved the largest value, in terms of log-likelihood (Log-L) and Durbin -Watson (D-W) statistic. The above results show that the two-way fixed effects model has better estimation results than the other three 
models. Therefore, this model was adopted to interpret the relationship between variables.

The lower half of Table 2 presents the test results on the spatial autocorrelation of the residual terms of the model. The lag of the Lagrange Multiplier (LM) test, denoted as LM-lag, was 0.2481 , failing to pass the significance test; the LM-error, denoted as LM-err, was 5.4157, which passed the significance test on the level of $5 \%$. The results show that the residual terms have obvious spatial autocorrelation. If not resolved, the spatial autocorrelation will lead to bias in model estimation.

The spatial autocorrelation of the residual terms cannot be eliminated by general models. Hence, spatial econometric models with two-way fixed effects were adopted to resimulate model (8). The estimated results of the SAR model and the SEM are compared in Table 3.

As shown in Table 3, the SAR model's spatial lag, $\mathrm{W}^{*}$ dep.var., was -0.0299 , failing to pass the significance test. Thus, the SAR model is not suitable for this research. By contrast, the SEM had a spatial error, $\mathrm{W}^{*}$ dep.var., of -0.2100 , which passed the the significance test on the level of $1 \%$. The comparison proves that the SEM is the best form of our spatial econometric model.

Compared with general models, the SEM output very large R-squared and Log-L, the same sign of the estimation coefficient of each variable, and a large t-statistic. This means the spatial econometric model optimized the results of general models. Therefore, the SEM was selected to interpret the estimation coefficient of each variable.

As shown in Table 3, the estimation coefficient of $L n P G D P$ and that of $\operatorname{Ln}\left(P G D P^{2}\right)$ of the SEM were positive and negative, respectively. Thus, there must be one inflection point of the EKC spatial model, which is in line with the basic form of the traditional EKC: economic growth has an inverted $U$ relationship with $\mathrm{CO}_{2}$ emissions. The relationship is divided by the inflection point into two stages (Figure 3 ).

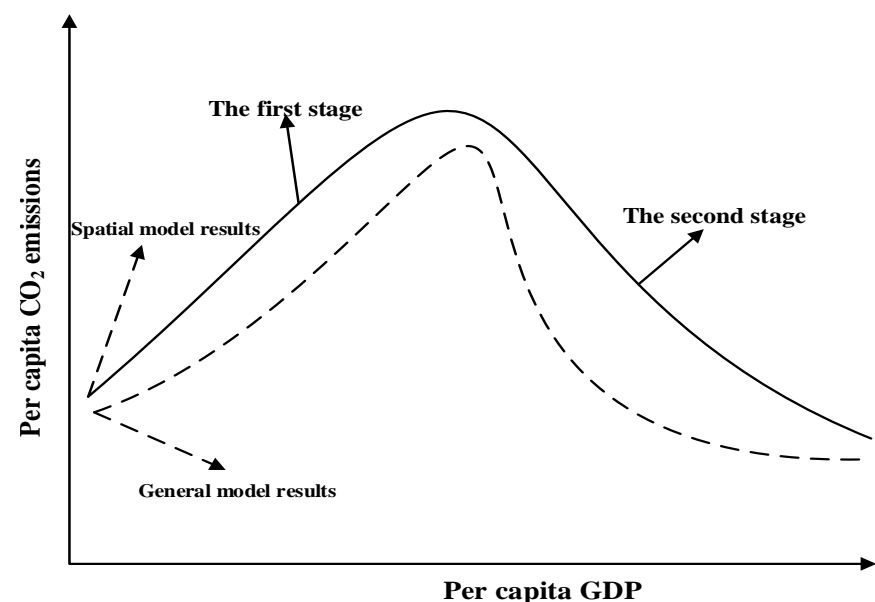

Figure 3. The inverted $U$ relationship between per capita GDP and per capita $\mathrm{CO}_{2}$ emissions

In the first stage, the estimation coefficient of LnPGDP was 0.9528 and significant on the $1 \%$ level. This means the rapid economic growth brings lots of $\mathrm{CO}_{2}$ emissions, when the economy just starts to develop. In general, economic growth is reflected in three dimensions: scale, structure and technology. When the economy just starts to develop, the government emphasizes the expansion of economic scale over the structural upgrading and the technical progress. That is why China's economic growth is featured by high investment, pollution and emissions. Under this extensive growth mode, the fast growing economy must be backed up by lots of production factors. The consumption of fossil energy takes up a large portion of production factors, which obviously increase the intensity of $\mathrm{CO}_{2}$ emissions

In the second stage, the estimation coefficient of $\operatorname{Ln}\left(P G D P^{2}\right)$ was -0.0282 and also significant on the $1 \%$ level. This means, with the continuous growth of per capita GDP, further economic growth suppresses $\mathrm{CO}_{2}$ emissions. It can be seen that, once economy surpasses a threshold, the environmental awareness will grow with the rising income, i.e. people will raise higher demand for high-quality eco-environment. Meanwhile, the government will gradually recognize the importance of low-carbon transformation of economic development, and promote the shift from scale to quality. At this time, the government will vigorously implement industrial upgrading and transformation, eliminate backward industries and reduce excess capacity. In addition, the government will encourage enterprises to adopt new low-carbon technologies and upgrade production equipment, thereby reducing the intensity of energy consumption and controlling emissions. Overall, $\mathrm{CO}_{2}$ emissions are cut down by structural optimization and advanced technologies, indicating that economic growth in the second stage helps to reduce $\mathrm{CO}_{2}$ emissions.

Judging by the estimated results, the control variables have different degrees of impact on $\mathrm{CO}_{2}$ emissions.

The industrial structure (IND) had a positive impact on per capita $\mathrm{CO}_{2}$ emissions on the significance level of $1 \%$, indicating that the proportion of the output of secondary industry in GDP promotes the per capita $\mathrm{CO}_{2}$ emissions. The result indicates that China is still in the stage of rapid industrialization, and industry takes and will take a large portion in national economy. This also means that fossil energy consumption remains high.

The energy consumption structure (ECS) had a positive impact on per capita $\mathrm{CO}_{2}$ emissions on the significance level of $1 \%$, indicating that the proportion of coal in the energy structure promotes the per capita $\mathrm{CO}_{2}$ emissions. This finding echoes with the relevant data: In 2017, coal took up $62 \%$ of all energies being consumed, while clean energies like nuclear power and hydropower occupied less than 20\%. As a traditional coal consumer, China still has a coal-dominated energy structure, which clearly promotes $\mathrm{CO}_{2}$ emissions.

The level of opening (OPL) had a negative impact on per capita $\mathrm{CO}_{2}$ emissions on the significance level of $5 \%$, indicating that import/export trade suppresses the per capita $\mathrm{CO}_{2}$ emissions. The result validates the previous assumption that: As China deepens foreign trade, the trade products will gradually shift from low-end products to high-tech products. The gradual shift promotes the low-carbon upgrading of regional industry, and lowers the intensity of energy consumption.

The environmental regulation (ERS) had a positive impact on per capita $\mathrm{CO}_{2}$ emissions on the significance level of $1 \%$, indicating that the rise in the investment on industrial pollution control actually promotes $\mathrm{CO}_{2}$ emissions. A possible reason is the immature system of environmental regulation in China. The excessive government intervention has not forced enterprises to reduce emissions, but distorted the resource allocation, creating the environmental paradox.

Figure 3 also compares the estimated results of general model and our spatial model. It can be seen that the estimated results of both models exhibited as inverted $\mathrm{U}$ curves. 
However, the inverted $U$ curve of our spatial model was higher and steeper than that of the general model. Therefore, the economic growth in our spatial model has greater impact on $\mathrm{CO}_{2}$ emissions than that in the general model. Moreover, the inflection point of our spatial model appeared earlier than that of the general model. Thus, the general model has a certain lag in EKC estimation, inducing errors in environmental policies.

\section{DISCUSSION}

Over the past 40 years, China has developed into the second largest economy in the world, with an annual economic growth rate of $9.5 \%$. The economic growth is accompanied by heavy energy consumption and severe eco-environmental problems. Being the largest $\mathrm{CO}_{2}$ emitter, China must take more energysaving and emissions reduction measures to achieve the goal of reducing the $\mathrm{CO}_{2}$ emission per unit of GDP by $40-45 \%$ before 2020. Unfortunately, neither the intensity of energy consumption nor that of $\mathrm{CO}_{2}$ emissions is expected to decline, for the country is striving to build a well-off society in an allround and further promoting industrialization and urbanization.

Against this backdrop, the Chinese government is faced with an arduous task: Under the premise of maintaining the healthy economic growth, controlling $\mathrm{CO}_{2}$ emissions within a reasonable range, without severely affecting energy supply and daily lives. To effectively promote energy-saving and emissions reduction, it is critical to explore the internal relationship between economic growth and $\mathrm{CO}_{2}$ emissions, and identify the influencing factors of $\mathrm{CO}_{2}$ emissions.

The traditional EKC model ignores the spatial dependence in the relationship between economic growth and $\mathrm{CO}_{2}$ emissions, which leads to errors in research conclusions. Referring to theories of spatial econometrics, this paper introduces the spatial effect into the traditional EKC model, and takes industrial structure, energy consumption structure, level of opening and environmental regulation as control variables. On this basis, an EKC spatial econometric model was established with multiple control variables, and used to verify if the relationship between economic growth and $\mathrm{CO}_{2}$ emissions in China satisfies the EKC model.

From a fresh perspective, this research validates the assumption that the relationship between economic growth and $\mathrm{CO}_{2}$ emissions can be illustrated as an EKC, estimates the EKC of the $\mathrm{CO}_{2}$ emissions in China in an accurate manner, and correctly predicts the form and inflection point of the curve. In addition, the influencing factors (other than economic growth) of $\mathrm{CO}_{2}$ emissions and their degree of impacts were analyzed accurately, enabling governments at all levels to formulate reasonable carbon reduction policies.

\section{CONCLUSIONS}

Energy depletion and environmental pollution are two major bottlenecks of sustainable development of economy in China. Thus, it is of great significance to coordinate the development of economy, energy and environment. This paper selects the panel data in 2000-2017 of 30 provinces as objects, estimates the $\mathrm{CO}_{2}$ emissions of each province, and calculates provincial per capita $\mathrm{CO}_{2}$ emissions. Next, the spatial autocorrelation coefficient and the LISA scatter plot were adopted to study the spatial effect of per capita $\mathrm{CO}_{2}$ emissions. Finally, the spatial effect was introduced to the traditional
EKC model, creating an EKC spatial econometric model about the relationship between economic growth and $\mathrm{CO}_{2}$ emissions. The research results are as follows:

First, the provinces differed greatly in per capita $\mathrm{CO}_{2}$ emissions. Based on the mean value in 2000-2017, the per capita $\mathrm{CO}_{2}$ emissions of Inner Mongolia, Ningxia, Shanxi, Tianjin, and Liaoning were all above 9.5 tons, while those of Hunan, Jiangxi, Guangxi, Sichuan and Hainan were all below 3.5 tons.

Second, the Global Moran's I values show a significant spatial correlation between provincial per capita $\mathrm{CO}_{2}$ emissions. The LISA scatter plot indicates that, in terms of per capita $\mathrm{CO}_{2}$ emissions, most provinces belong to the cluster areas of high values $(\mathrm{H}-\mathrm{H})$ and low values $(\mathrm{L}-\mathrm{L})$, while only a few belong to the areas of spatial outliers. The results indicate the local spatial heterogeneity of provincial per capita $\mathrm{CO}_{2}$ emissions.

Third, the EKC spatial econometric model outperforms the general econometric model in estimation accuracy. Besides, the EKC spatial econometric model shows that the economic growth has a significant inverted $\mathrm{U}$ relationship with $\mathrm{CO}_{2}$ emissions. In other words, with the growth in economy, the $\mathrm{CO}_{2}$ emissions firstly increase and then decrease. The twostage relationship obeys the basic form of the traditional EKC.

Fourth, the estimated results of control variables indicate that $\mathrm{CO}_{2}$ emissions are clearly promoted by industrial structure, energy consumption structure and environmental regulation, but suppressed by the level of opening.

\section{REFERENCES}

[1] Azomahou, T., Laisney, F., Van, P.N. (2006). Economic development and $\mathrm{CO}_{2}$ emissions: A nonparametric panel approach. Journal of Public Economics, Elsevier, 90(6): 1347-1363. https://doi.org/10.1016/j.jpubeco.2005.09.005

[2] Agras, J., Chapman, D. (1999). A dynamic approach to the Environmental Kuznets curve hypothesis. Ecological Economics, 28(2): 267-277. https://doi.org/10.1016/S0921-8009(98)00040-8

[3] Grossman, G.M., Krueger, A.B. (1991). Environmental impacts of the North American free trade agreement. National Bureau of Economics Research Working paper, No.W3914. https://doi.org/10.3386/w3914

[4] Lindmark, M. (2002). An EKC-Pattern in historical perspective: carbon dioxide emissions, technology, fuel prices and growth in Sweden 1870-1997. Ecological Economics, 42(1/2): https://doi.org/10.1016/S0921-8009(02)00108-8

[5] Nasir, M., Rehman, F.U. (2011). Environmental Kuznets curve for carbon emissions in Pakistan: An empirical investigation. Energy Policy, 39(3): 1857-1864. https://doi.org/10.1016/j.enpol.2011.01.025

[6] Jalil, A., Mahmud, S F. (2009). Environment Kuznets curve for $\mathrm{CO}_{2}$ emissions: A cointegration analysis for China. Energy Policy, 37(12): 5167-5172. https://doi.org/10.1016/j.enpol.2009.07.044

[7] Du, L.M., Wei, C., Cai, S.H. (2012). Economic development and carbon dioxide emissions in China: provincial panel data analysis. China Economic Review, 23(2): 371-384. https://doi.org/10.1016/j.chieco.2012.02.004

[8] Wang, F., Yang, X., Tian, Y., Wang, S.P. (2018). 
Empirical Study on the Relationship between Carbon Emission and Economic Growth Based on EKC Hypothesis. Ecological Economy, 34(10): 19-23.

[9] Hu, Z.Y., Tang L.W., Su, J. (2013). Carbon emissions and economic growth: dynamic spatial effect and EKC reexamination. Journal of Shanxi University of Finance \& Economics, 35(12): 30-37.

[10] Dinda, S. (2004). Environmental Kuznets curve hypothesis: a survey. Ecological Economics, 49(4): 431455. https://doi.org/10.1016/j.ecolecon.2004.02.011

[11] Mcconnell, K.E. (1997). Income and the demand for environmental quality. Environment and Development Economics, 2(4): 380-396. https://doi.org/10.1017/S1355770X9700020X

[12] Stern, D.I. (2004). The rise and fall of the Environmental Kuznets curve. World Development, 32(8): 1419-1439. https://doi.org/10.1016/j.worlddev.2004.03.004

[13] Taskin, F., Zaim, O. (2000). Searching for a Kuznets curve in environmental efficiency using Kernel estimation. Economics Letters, 68(2): 217-223. https://doi.org/10.1016/S0165-1765(00)00250-0

[14] Wang, K.M. (2012). Modelling the nonlinear relationship between $\mathrm{CO}_{2}$ emissions from oil and economic growth. Economic Modelling, 29(5): 1537-1547. https://doi.org/10.1016/j.econmod.2012.05.001

[15] Anselin, L., Rey, S. (1991). Properties of tests for spatial dependence in linear regression models. Geographical Analysis, 23(2): 112-131. https://doi.org/10.1111/j.15384632.1991.tb00228.x

[16] Li, Y.M., Zhang, L., Cheng, X.L. (2010). A decomposition model and reduction approaches for carbon dioxide emissions in China. Resources Science, 32(2): 219-221.

[17] Moran, P.A.P. (1948). The interpretation of statistical maps. Journal of the Royal Statistical Societ, Series B (Methodological), 10(2):
https://www.jstor.org/stable/2983777

[18] Moran, P.A. (1950). Notes on continuous stochastic phenomena. Biometrika, 37(1/2): 17-23. https://doi.org/10.2307/2332142

[19] Cole, M.A. (2004). US environmental load displacement: examining consumption, regulations and the role of NAFTA. Ecological Economics, 48(4): 439-450. https://doi.org/10.1016/j.ecolecon.2003.10.016

[20] Anselin, L. (2013). Spatial econometrics: Methods and models. Springer Science \& Business Media.

[21] Haining, R. (1993). Spatial data analysis in the social and environmental sciences. Cambridge University Press. 